\title{
LOCAL USE OF ANTIFIBRINOLYTIC AGENT IN PREVENTION OF ALVEOLAR OSTEITIS. (A CLINICAL STUDY)
}

\author{
Hossam El-Din Mohamed Ali*
}

\begin{abstract}
The study was done to evaluate the effect of local use of antifibrinolytic agent in the prevention of alveolar osteitis after extraction of impacted mandibular $3^{\text {rd }}$ molar. The study took place on 90 consecutive patients (45 patients in each group). After surgical extraction the sockets were irrigated immediately with $10 \mathrm{ml}$ of solution (tranexamic acid or placebo) for $2 \mathrm{~min}$. 4 times / day (every 6 hours) for 2 days. Patients returned in five to seven days for suture removal complaining of postoperative pain were examined to verify the severity of the localized osteitis which graded as mild, moderate, or severe according to the patient's stated degree of pain which scored according to visual analogue scale. The incidence of dry sockets in the group treated with $10 \%$ tranexamic acid was $6.6 \%$ compared with $28.8 \%$ in the sockets treated with placebo. In addition, the untreated group presented with dry sockets judged to be more severe.
\end{abstract}

\section{INTRODUCTION}

The most common complication following the extraction of teeth is alveolar osteitis (AO). AO is a complication seen in $0.5-5 \%$ of routine extractions. It has been reported to occur more often following the extraction of impacted mandibular third molars. Studies have reported incidence rates as high as $37.5 \%$ following the surgical extraction of impacted lower third molars ${ }^{(1)}$. The denuded alveolar bone may be painful and tender. Some patients may also complain of intense, continuous pain irradiating from the empty socket to the ipsilateral ear, temporal region or the eye. Regional lymphadenopathy is also noted occasionally, trismus is a rare occurrence $^{(2)}$. AO remains a common postoperative problem resulting in pain, lost days at work, loss of productivity, and return surgical practice/hospital visits. This is also costly to the surgeon, as $45 \%$ of patients who develop AO typically require at least four additional postoperative visits in the process of managing this condition ${ }^{(3)}$.

$\mathrm{AO}$ is generally believed to be of multifactorial origin, oral micro-organisms, difficulty and trauma during surgery, roots or bone fragments remaining in the wound, excessive irrigation or curettage of the alveolus after extraction, physical dislodgement of the clot, local blood perfusion, oral contraceptives and smoking have been implicated

\footnotetext{
* Lecturer of Oral and Maxillofacial Surgery, Faculty of Dental Medicine (Assiut), Al-Azhar University
} 
most commonly as ideological, aggravating and precipitating factor ${ }^{(4)}$.

The prevention of the AO can be divided into non-pharmacological and pharmacological preventive measures. The non-pharmacological preventive measures include a comprehensive history of the patient with identification, and if possible, elimination of risk factors associated with an increased risk to develop $\mathrm{AO}{ }^{(4)}$. The pharmacological prophylactic interventions relate to one or more of the following groups antibacterial agents ${ }^{(5)}$, antiseptic agents ${ }^{(6)}$, antifibrinolytic agents ${ }^{(7)}$, steroid anti-inflammatory agents ${ }^{(8)}$, attending dressings ${ }^{(9)}$ and clot support agents ${ }^{(10)}$.

Antifibrinolytic agents can be used topically or systemically as oral or intravenous formulations. All agents can be used before, during or after dental procedures ${ }^{(11)}$. Clinical trials to reduce the clot destruction by prophylactic use of antifibrinolytic compounds have demonstrated that local use has probably been superior to general use ${ }^{(12)}$. AMCA binds to lysine binding sites on plasminogen and plasmin. This mechanism blocks the binding of plasmin to fibrin, thus acting as a potent inhibitor of fibrinolysis ${ }^{(11)}$.

This study was a trial to evaluate the effectiveness of local use of tranexamic acid in prevention of $\mathrm{AO}$ of impacted lower wisdom.

\section{MATERIAL AND METHODS}

A clinical study took place at the Oral and Maxillofacial Surgery Outpatient Clinic, Faculty of Dentistry, Al-Azhar University, Assiut branch, on 90 consecutive patients (45 patients in two groups) who had had an impacted mandibular third molar removed. Extractions were classified as soft tissue impactions (requiring no bone removal) and bony impactions. Informed consent was obtained from all patients before any study procedures were performed.
All the patients were free from any local or systemic condition that may interfere with the healing process. The exclusion criteria include: unwilling to participate, reluctant to avoid consuming antibiotics, failure to attend follow up sessions, the presence of psychological condition or receiving sedatives, any need for antibiotic prophylaxis, pregnancy, allergy to medication. Patients with acute pericoronitis were operated on after objective and subjective symptoms of pericoronitis had ceased.

Preparation of tranexamic acid:

An active solution of $10 \mathrm{ml}$ of tranexamic acid was prepared by using commercially availably ampoules of $10 \%$ tranexamic acid (Kapron).Each ampoule contained $5 \mathrm{ml}$ of $10 \%$ tranexamic acid which was diluted with $5 \mathrm{ml}$ of plain water. The resulting mixture of 5\% tranexamic acid used for local irrigation and in mouth rinsing for two minutes ${ }^{(13)}$.

Patients were anaesthetised with Mepecaine HCL 2\% with Levonordefrin HCL The anaesthetic blocked the mandibular, the lingual and the buccal nerves. An oblique incision was made over the impacted third molar, and an envelope type of flap was reflected. Overlying bone was removed with a high-speed rotary instrument, and the tooth was sectioned with the same instrument. These sections were elevated from the bone, and the area was debrided and irrigated with saline solution.

The extraction sites were irrigated immediately after extraction with $10 \mathrm{ml}$ of medication package solution. The flap was then repositioned and sutured with 3-O black silk. Before leaving the outpatient clinic, the patients received 7 medication packages containing the solution, the patients were instructed to use the medication as mouthwash for $2 \mathrm{~min} .4$ times/day (every 6 hours) for 2 days. The solution was to be expectorated after rinsing. The patients were asked not to eat or drink during the first hour after using the mouthwash. 
Plastic containers for oral irrigation with AMCA or placebo were supplied in neutral, randomly numbered packets and the code was unknown to the operators. The operators did not know the solutions used and the content of plastic containers. The data were recorded via a number code on the patient's charts. The operators who performed the surgical procedures did not see the patients for follow-up, thus permitting better evaluation of the postoperative results. Patients were given appointments to return in five to seven days for suture removal. Patients who returned complaining of postoperative pain were examined to determine the cause. The integrity of the clot was evaluated by socket irrigation followed by visual and tactile inspection. Healing was assessed based on healing stage. The stages as follows: no clot formation, clot formed, clot stabilized, 1/2 of socket epithelialized and covered, epithelialization almost complete, the wound closed and socket appears closed with normal mucosa coverage. Local osteitis was diagnosed with absence of a complete clot, tenderness of the alveolus to probe, constant pain beginning three to four days after the operation, radiation of the pain to the preauricular area of the involved side, inadequate control of pain by analgesics, and prompt relief of pain by a eugenol dressing.

The severity of the localized osteitis was graded as (mild), (moderate), or (severe) according to the patient's stated degree of pain which scored according to visual analogue scale which scaled 0-10, 0 mean no pain, 1,2,3 mean mild pain, 4,5,6 mean moderate pain, 7,8,9,10 mean severe pain.

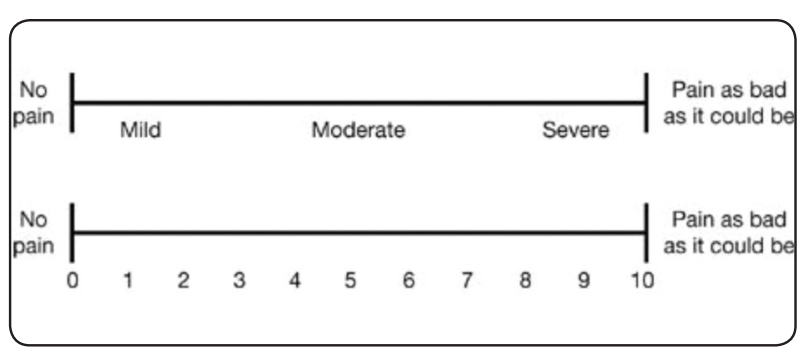

\section{RESULTS}

Ninety patients were included in the study (37 male and 53 female) patients have completed the study. They ranged in age between 21 and 38 years with a mean age of 29 years. There was a highly significant $(\mathrm{P}<0.005)$ reduction in the total number of cases of $\mathrm{AO}$ in the treated sockets with AMCA (three of 45 cases, $6.6 \%$ ) compared with the treated sockets with placebo (13 of 45 cases, 28.8\%) (Table1). There was a smaller but still significant $(\mathrm{P}<0.05)$ reduction achieved by using AMCA with soft tissue impactions. In the soft tissue category, there were only three cases of AO after 16 treated extractions with placebo $(18.7 \%)$, but none occurred in AMCA treated sockets. The greatest reduction in AO occurred with bony impactions. In this category, AO developed in only ten of 29 treated sockets with placebo (34.3\%) while only three of $29(10.3 \%)$ treated sockets with AMCA were so involved.

TABLE (1) Effect of AMCA on the incidence of AO.

\begin{tabular}{|c|c|c|c|c|}
\hline & \multicolumn{2}{|c|}{ Placebo group } & \multicolumn{2}{c|}{ AMCA group } \\
\hline & Impaction & Osteitis \% & Impaction & Osteitis \% \\
\hline $\begin{array}{c}\text { Soft tissue } \\
\text { impaction }\end{array}$ & 16 & $3(18.7)$ & 16 & $0^{*}(0)$ \\
\hline $\begin{array}{c}\text { Bony } \\
\text { impaction }\end{array}$ & 29 & $10(34.3)$ & 29 & $3^{+}(10.3)$ \\
\hline Total cases & 45 & $13(28.8)$ & 45 & $3^{+}(6.6)$ \\
\hline
\end{tabular}

* Chi-square analysis significant at $P<0.05$.

${ }^{+}$Chi-square analysis significant at $P<0.005$.

An attempt was made to grade the severity of the AO based on patient discomfort and relief afforded by a eugenol-based dressing. These data are presented in Table $2 \&$ fig 1 . The incidence of moderate and severe pain in the AMCA treated cases (one) was significantly less $(\mathrm{P}<0.005)$ than in the treated cases with placebo (ten). 
TABLE (2) Severity of AO Related to Surgical Complexity and use of AMCA.

\begin{tabular}{|c|c|c|}
\hline $\begin{array}{c}\text { Type of } \\
\text { extraction }\end{array}$ & $\begin{array}{l}\text { Graded of } \\
\text { Severity }\end{array}$ & $\begin{array}{c}\text { Frequency of Osteitis for } \\
\text { Each Severity Grade }\end{array}$ \\
\hline \multicolumn{3}{|c|}{ Placebo group } \\
\hline \multirow{3}{*}{$\begin{array}{l}\text { Soft tissue } \\
\text { impaction }\end{array}$} & Mild & 1 \\
\hline & Moderate & 2 \\
\hline & Severe & 0 \\
\hline \multirow{3}{*}{$\begin{array}{c}\text { Bony } \\
\text { impaction }\end{array}$} & Mild & 2 \\
\hline & Moderate & 4 \\
\hline & Severe & 4 \\
\hline \multicolumn{3}{|l|}{ AMCA group } \\
\hline \multirow{3}{*}{$\begin{array}{l}\text { Soft tissue } \\
\text { impaction }\end{array}$} & Mild & 0 \\
\hline & Moderate & 0 \\
\hline & Severe & 0 \\
\hline \multirow{3}{*}{$\begin{array}{c}\text { Bony } \\
\text { impaction }\end{array}$} & Mild & 2 \\
\hline & Moderate & 1 \\
\hline & Severe & 0 \\
\hline
\end{tabular}

-Chi-square analysis of the incidence of moderate and severe cases of $A O$ comparing Placebo group and AMCA group cases showed significant $(P<0.005)$ reduction in degree of pain in the treated cases with AMCA.

\section{DISCUSSION}

$\mathrm{AO}$ is not considered a disease of bacterial infection, but a healing disturbance due to loss of blood clot in extraction socket. Most investigators believe that surgical trauma and local inflammation play major roles in the clinical condition of AO. Birn $^{(14)}$ showed increased fibrinolytic activity and activation of plasminogen to plasmin in the presence of tissue activators in dry sockets which thought to affect the integrity of the postextraction blood clot. Birn ${ }^{(15)}$ also stated that the increase in fibrinolysis was unlikely to dissolve the blood clot before the second day after surgery, because the clot contains antiplasmin, which must be neutralized before clot dissolution can occur which explain the suffering of patients from pain after the $3^{\text {rd }}$ day postextraction.

The AMCA is one of the most potent antifibrinolytic drugsused in general and local therapy and present in tissues twice as long as in plasma. AMCA and related compounds interfere biochemically with the normal functional interactions between fibrin and plasmin and between plasminogen and tissue activator which prevent fibrinolysis of the blood clot of the socket ${ }^{(16)}$. Based on these associations, there is a pharmacological rationale for the use of a locally effective AMCA in extraction sites to reduce the incidence of dry sockets.

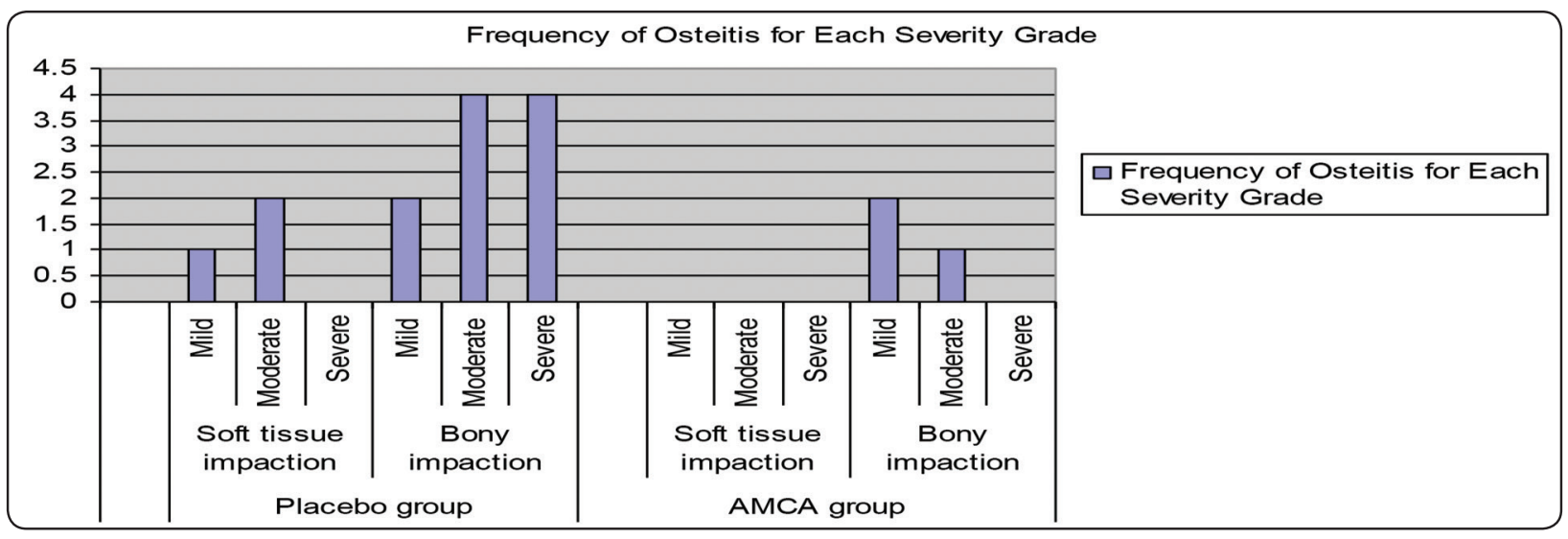

Fig. (1) Frequency of Osteitis for Each Severity Grade. 
The reason why the systemic use of AMCA did not have the expected effect in preventing the development of AO may be due to the concentration of AMCA in the blood and the tissue has been too small, and acted in too short a time, to counteract the fibrinolytic activity in the socket as in the study of Martin Ritzau ${ }^{(12)}$.

Another study ${ }^{(16)}$ was failed in the prevention of AO by using a cone containing AMCA locally in the socket which may be due to the carrier material can potentially become a nidus for infection or foreign body reaction which may cause retardation of healing by the cones potted in the socket.

Anand K.P ${ }^{(17)}$ et al used the tranexamic acid locally (gelfoam soaked in AMCA) and systemically in a trial for prevention of $\mathrm{AO}$ after simple extraction and they recommended this treatment modality despite placing of gelfoam in the socket and suturing it may retard or delay the healing.

Our purpose in this study was to overcome this minor complication by using this simple, inexpensive tranexamic acid locally alone without placing any material in the socket to prevent retardation of healing. Antifibrinolytic agents, when used locally in the extraction site, have been shown to decrease the incidence of AO.

The AMCA did have the expected effect in preventing the development of $\mathrm{AO}$ is might be of two explanations: (1) The local concentration of AMCA in the saliva and oral cavity has been too large, and acted for a long time, to counteract the fibrinolytic activity in the socket. (2) AMCA has reached the postextraction socket locally so the cavity did not affected by the thrombosed capillaries in the wall of the socket. Both explanations are possible and might act simultaneously.

The results of this study indicated that using AMCA alone is a simple, safe and effective medicament for decreasing both the incidence and the severity of AO following removal of soft tissue or bony impacted mandibular third molars.

\section{REFERENCE}

1- L.E. Almeida S. Pierce, K. Klar, K. Sherman: Effects of oral contraceptives on the prevalence of alveolar osteitis after mandibular third molar surgery: a retrospective study. Int. J. Oral Maxillofac. Surg. 2016; 5: 22:1-4.

2- H. Ghaeminia , Th. J. M Hoppenreijs. T. Xi, J. P. Fennis , T. J Maal, S. J. Bergé, G. J. Meijer: Postoperative socket irrigation with drinking tap water reduces the risk of inflammatory complications following surgical removal of third molars: a multicenter randomized trial. Clin Oral Invest. 2016; 27 February.

3- Bienstock DA, Dodson TB, Perrott DH, Chuang SK: Prognostic factors affecting the duration of disability after third molar removal. J Oral Maxillofac Surg.2010; 69 (5): 1272-1277.

4- I. R. Blum: Contemporary views on dry socket (alveolar osteitis): a clinical appraisal of standardization, aetiopathogenesis and management: a critical review. Int. J. OralMaxillofac. Surg. 2002; 31: 309-317.

5- Jasleen Kaur, Rushik Raval, Anupam Bansal, Vinod Kumawat: Repercussions of intraalveolar placement of combination of $0.2 \%$ chlorhexidine \& $10 \mathrm{Mg}$ metronidazole gel on the occurrence of dry sockets- A randomized control trial. J Clin Exp Dent. 2017;9(2): 284-8.

6- Amare Teshome: The efficacy of chlorhexidine gel in the prevention of alveolar osteitis after mandibular third molar extraction: a systematic review and meta-analysis. Teshome BMC Oral Health.2017;17:82.

7- K.P. Anand, Swadheena Patro, Abhijita Mohapatra, Sumita Mishra: The Efficacy of Tranexamic Acid in the Reduction of Incidence of Dry Socket: An Institutional Double Blind Study. 2015; 9(9): 25 -28.

8- Hyrkas T: Effect of preoperative single doses of diclofenac and methylprednisolone on wound healing. Scand J Plast Reconstr Surg Hand Surg.1994 Des; 28(4)275-8.

9- Sayed Faizel - Shaji Thomas - V. Yuvaraj. S. Prabhu • Geetha Tripath: Comparision Between Neocone, Alvogyl and Zinc Oxide Eugenol Packing for the Treatment of Dry Socket: A Double Blind Randomized Control Trial. J. Maxillofac. Oral Surg. 2014; 6 July.

10- Hooley JR, Golden DP. The effect of polylactic acid granules on the incidence of alveolar osteitis after mandibular third molar surgery. A prospective randomized study. Oral Surg Oral MED Oral Pathol Oral Radiol Endod. 1995;sep80 (3): 279-83. 
11- Karin PM van Galen, Eveline T Engelen, Evelien PMauserBunschoten, Robert JJ van Es, Roger EG Schutgens: Antifibrinolytic therapy for preventing oral bleeding in patients with hemophilia or VonWillebrand disease undergoing minor oral surgery or dental extractions. Cochrane Database of Systematic Reviews 2015, Issue 12

12- Ritzau, M.: The prophylactic use of tranexamic acid (Cyklokapron $\left.{ }^{\circledR}\right)$ on alveolitis sicca dolorosa. Int. J. Oral Surg. 1973; 2: 196-199.

13- Gasper R, Brenner B, Ardekian L, et al: Use of tranexamic acid mouthwash to prevent postoperative bleeding in oral surgery patients on oral anticoagulant medication. Quintessence Int 1997; 28: 375.
14- Birn H. Etiology and pathogenesis in fibrinolytic alveolitis (dry socket). Int J Oral Surg 1973;2:211-63.

15- Birn H. Bacteria and fibrinolytic activity in dry socket. Acta Odontol Scand 1970;28:773-83.

16- Gersel-Pedersen N. Tranexamic acid in alveolar sockets in the prevention of alveolitis sicca dolorosa. Int J Oral Surg 1979; 8: 421-429.

17- K.P.Anand, Swadheena Patro, Abhijita Mohapatra, Sumita Mishra: The Efficacy of Tranexamic Acid in the Reduction of Incidence of Dry Socket: An Institutional Double Blind Study. J Clin Diag Resear 2015; 9: 25 - 28. 